\title{
Desain Sistem Pemantauan Kualitas Air pada Perikanan Budidaya Berbasis Internet of Things dan Pengujiannya
}

\author{
Murie Dwiyaniti, Rika Novita W, Tohazen \\ Electrical Engineering, Politeknik Negeri Jakarta \\ J1 Prof.Dr.GA Siwabessy, Kampus Baru UI Depok 16425 \\ murie.dwiyaniti@elektro.pnj.ac.id
}

Diterima: 7 Oktober 2019. Disetujui: 20 November 2019. Dipublikasikan November 2019

\begin{abstract}
Abstrak - Memonitor kualitas air pada perikanan budidaya sangatlah penting. Hal ini terkait dengan upaya mengoptimalkan pertumbuhan ikan dan meningkatkan hasil produksi. Umumnya kegiatan ini dilakukan secara manual, yaitu dengan mengambil contoh air kolam pada pagi, siang, dan malam hari, lalu hasil pengukuran dianalisa. Hal ini sangat tidak efektif. Sehingga pada penelitian ini, kami merancang sistem pemonitor kualitas air yang dapat memastikan kondisi air secara real time, memeriksa nilai parameter melalui Smartphone, dan menerima pemberitahuan alarm jika terjadi perubahan nilai diluar rentang nilai yang telah ditentukan. Sistem ini terdiri dari tiga bagian yang saling terintegrasi yaitu (1) empat sensor yang penting dalam pertumbuhan ikan yaitu, DO, suhu, pH, dan salinitas; (2) RTU berbasis mikrokontroler ESP32 dan ADS115; (3) Blynk. Sistem bekerja dimulai dari pembacaan data oleh sensor, data tersebut dikonversikan oleh ADS1115 untuk diolah oleh ESP32, kemudian hasilnya ditampilkan melalui aplikasi Blynk (IoT) dalam smartphone. Hasil pengujian menunjukkan bahwa sistem ini dapat berfungsi dengan baik yang dibuktikan oleh: (1) terbacanya data dari sensor, (2) Alarm berbunyi dan notifikasi alarm terbaca di smartphone apabila nilai parameter diluar rentang yang telah ditentukan.
\end{abstract}

Kata Kunci: kualitas air; iot; esp32; blynk; perikanan budidaya

\section{PENDAHULUAN}

Perikanan budidaya merupakan salah satu sektor produksi pangan yang sangat menjanjikan. Proyeksi bisnis di Indonesia mengindikasikan bahwa perikanan budidaya akan tumbuh hingga lebih dari 10,1 ton per tahun, menciptakan 8,9 juta lapangan kerja yang setara dengan pekerjaan purna-waktu dalam bidang produksi dan akan menjadi sektor dengan nilai produksi USD 39,5 miliar pada tahun 2030 [1]. Produksi perikanan budidaya Indonesia antara lain rumput laut, ikan nila, lele, bandeng, udang, dan tuna. Namun untuk menghasilkan produksi perikanan budidaya yang unggul dan optimal diperlukan kualitas air yang baik. Kualitas air yang berpengaruh pada pertumbuhan ikan, antara lain oksigen terlarut (DO), suhu, pH, dan salinitas [2].

Perubahan parameter kualitas air misalnya pada perubahan suhu akan menyebabkan nafsu makan menurun dan banyak kalori yang hilang sehingga dapat menyebabkan kematian [3]. Setiap perubahan parameter kualitas air diluar nilai rentang standar hidup ikan berdampak pada pola hidup dan perkembangannya bahkan dapat meyebabkan kematian. Oleh karena itu diperlukan pengukuran kualitas air secara real time dan pengendalian parameter agar tetap konstan direntang nilai yang diijinkan.

Peralatan sistem pengendali dan pemonitor kualitas air secara real time berbasis IoT telah banyak dibuat dengan mikrokontroler Arduino yang pengiriman datanya melalui sms gateway [2, 4, 5], embedded web server [6], zigbee [7, 8], Raspberry pi [9] dan LabVIEW [10]. Namun namun belum ada yang membuat sistem pengendali dan pemonitor kualitas air dengan mikrokontroler ESP32 yang terhubung dengan ADS115. Metode pengiriman data dan display data juga belum ada yang menggunakan Blynk sebagai platform IoT. Sehingga penelitian ini membuat rancangan sistem dengan pengendali ESP32 terintegrasi dengan ADS1115 dan pemonitor data melalui platform IoT Blynk. Sistem ini juga dilengkapi dengan alarm yang dapat memberikan notifikasi kepada owner melalui smartphone apabila terjadi perubahan nilai parameter yang diluar rentang yang ditentukan. Selain itu, rekaman data selama satu hari akan terkirim ke owner melalui email apabila owner menginginkan. 


\section{TINJAUAN PUSTAKA}

Permasalahan utama yang sering ditemukan dalam kegagalan produksi budidaya perikanan khususnya udang vannamei adalah buruknya kualitas air. Oleh karena itu, manajemen kualitas air selama proses pemeliharaan mutlak diperlukan. Beberapa parameter kulitas air yang sering diukur dan berpengaruh pada pertumbuhan udang yaitu oksigen terlarut (DO), karbondioksida bebas, suhu, $\mathrm{pH}$, salinitas, amonia, dan nitrit.

Pengukuran diupayakan secara real time dan online sehingga owner tidak perlu berada di kolam/tambak. Owner cukup melihat data dari smartphone/tablet. Pengukuran secara real time memerlukan sensor yang dapat diintegrasikan dengan mikrokontroler.

\section{A. Mikrokontroler ESP32}

ESP32 merupakan mikrokontroler dual-core yang terdiri dari dua CPU Harvard Xtensa LX6, di mana semua embedded memory, external memory dan peripheral terletak di bus data pada CPU [11]. Arsitektur ESP32 dapat dilihat pada Gambar 1. Fitur ESP32 antara lain adanya antena (built in), $R F$ balun, penguat daya, low-noise receive amplifier, filter, dan modul manajemen daya. ESP32 juga bekerja dengan konsumsi daya sangat rendah melalui fitur hemat daya termasuk fine resolution clock gating, multiple power modes, and dynamic power scaling. Selain itu pada ESP32 terdapat Wi-Fi yang cepat, GPIO yang lebih, dan mendukung Bluetooth Low Energy [11]. Sehingga ESP32 banyak digunakan untuk koneksi IoT.

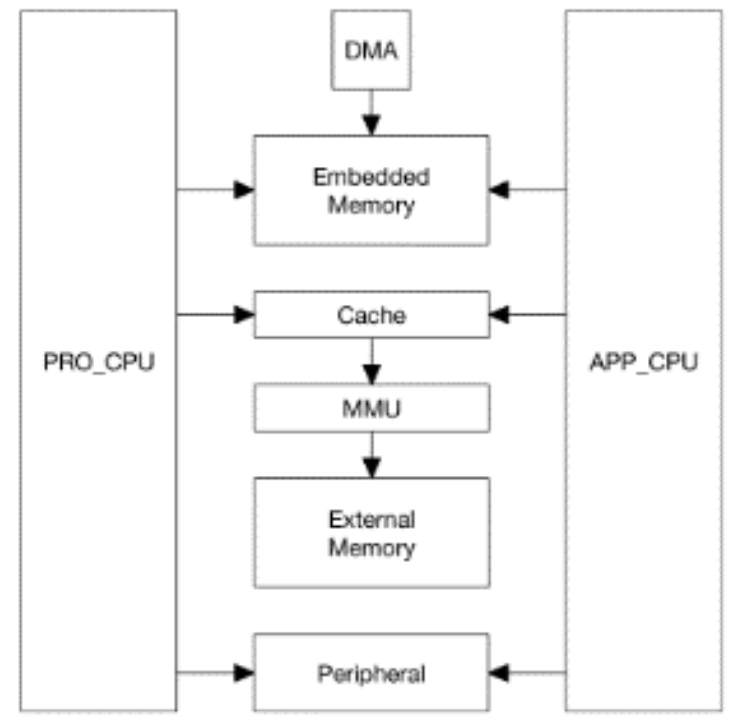

Gambar 1 Arsitektur Sistem ESP32 [11]

B. Analog Digital Converter (ADC)

Pada penelitian ini digunakan ADS1115 sebagai konverter untuk mengubah data analog menjadi digital. Umumnya data sensor adalah analog berupa tegangan sehingga perlu dikonversi menjadi digital menggunakan ADC. ADS115 memiliki komunikasi I2C, resolusi 16 bit, 4 channel, dan range tegangan 2-5,5 Volt [12].

\section{Sensor}

Sensor yang digunakan pada penelitian ini ada 4 jenis, yaitu sensor suhu, pH, salinitas dan DO. Sensor suhu menggunakan type LM35DZ dari Texas Instrument. Sensor ini dikemas dalam bentuk kedap air sehingga dapat dicelupkan ke dalam air. Akurasi pengukuran LM35DZ menggunakan fungsi transfer linier seperti persamaan 1 [13].

Dimana :

$$
\mathrm{V}_{\text {OUT }}=10 \mathrm{mV} /{ }^{\circ} \mathrm{C} \times \mathrm{T}
$$

$\mathrm{V}_{\text {OUT }}=$ Tegangan keluaran LM35DZ

$\mathrm{T} \quad=$ suhu dalam derajat celcius

Sensor $\mathrm{pH}$ mempunyai spesifikasi tegangan suplai $3,3-5,5 \mathrm{~V}$, tegangan output $0-3 \mathrm{~V}$, range deteksi $0-14$, range suhu $5-60^{\circ} \mathrm{C}$, zero point $7 \pm 0,5$, response time $<2 \mathrm{~min}$ [14]. Sensor $\mathrm{pH}$ digunakan untuk mengukur kadar keasaman air.

Untuk mengukur kandungan oksigen dalam air menggunakan sensor DO. Pada penelitian ini, tipe yang digunakan adalah EZO-DO dari Atlas Scientific yang memiliki spesifikasi range $0,01-100+\mathrm{mg} / \mathrm{L}$, 0,1-400+ \% saturation, accuracy +/snip- 0,05 mg/L, Response time 1 reading per sec, Supported probes any galvanic probe, data protocol UART dan I2C, operating voltage 3,3-5V, data format ASCII [15].

\section{Blynk Platform IoT}

Blynk merupakan salah satu platform IoT yang dapat digunakan untuk mengontrol (sekunder) dan memonitor berbagai data dari sensor secara real time selama ada jaringan internet. Penggunaan aplikasi Blynk sangat mudah hanya dengan metode drag and drop widget. Dengan platform Blynk dapat mengontrol peralatan listrik seperti lampu, valve, dan lain-lain.

\section{METODE PENELITIAN}

Metode penelitian terdiri dari tiga bagian yaitu (1) perancangan arsitektur sistem; (2) pembuatan perangkat keras yang digunakan untuk implementasi; dan (3) pembuatan perangkat lunak yang mendeskripsikan fungsi masing-masing komponen.

\section{A. Arsitektur Sistem}

Komponen yang terintegrasi pada sistem ini adalah modul ESP32, ADC dengan tipe ADS1115, Sensor, basis data, Layanan IoT platform Blynk, aplikasi mobile, dan aplikasi Desktop. Gambar 2 menunjukkan arsitektur sistem : input, proses, output, konektivitas dan tampilan data. 


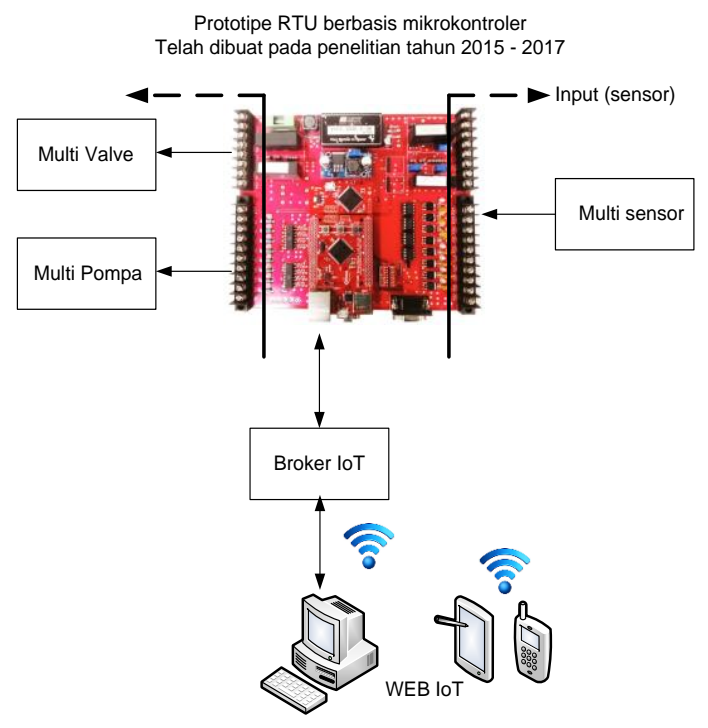

Gambar 2 Arsitektur Sistem

Pada bagian ini terdapat empat sensor yang digunakan, yaitu sensor suhu analog LM35DZ, sensor analog pH SEN 0161-V2, sensor salinitas, dan sensor Atlas Dissolved Oxygen. Sensor suhu, $\mathrm{pH}$ dan salinitas terkoneksi dengan ADS115 untuk mengkonversi data analog menjadi digital lalu data terbaca oleh ESP32. Sedangkan Sensor DO mengirimkan data melalui UART (Universal Asynchronous Transmitter-Receiver) ke ESP32. Pengukuran data dilakukan dengan merendam semua sensor ini ke dalam air.

Konektivitas data dari sensor ditransmisikan melalui $W i$-fi yang ada dalam ESP32. Wi-fi pada ESP32 bekerja di pita frekuensi 2,4 GHz dan transfer data up to $150 \mathrm{Mbit} / \mathrm{s}$. Modul ESP32 digunakan sebagai pengendali untuk menerima dan mengirimkan data ke internet. Data dari modul ESP32 ditampilkan pada Blynk yang merupakan platform aplikasi OS mobile berbasis internet.

\section{B. Perangkat Keras}

Pembuatan perangkat keras menggunakan koper aluminium dengan ketebalan material body 5 $\mathrm{mm}$, ukuran Luar, $27 \times 23 \times 7 \mathrm{~cm}$, dan ukuran bagian dalam 26,5x1,5x6cm. Dalam koper ini ditempatkan 5x5 baterai Li-Ion 18650 Cylindrical berkapasitas $2700 \mathrm{mAh}$ dengan tegangan $3.7 \mathrm{~V}$ yang dihubungkan secara paralel, modul RTU ESP32, sensor pH, sensor suhu, sensor salinitas, sensor DO dan tablet ukuran layar 7 inch. Gambar 3 menunjukkan perangkat keras di koper aluminium.

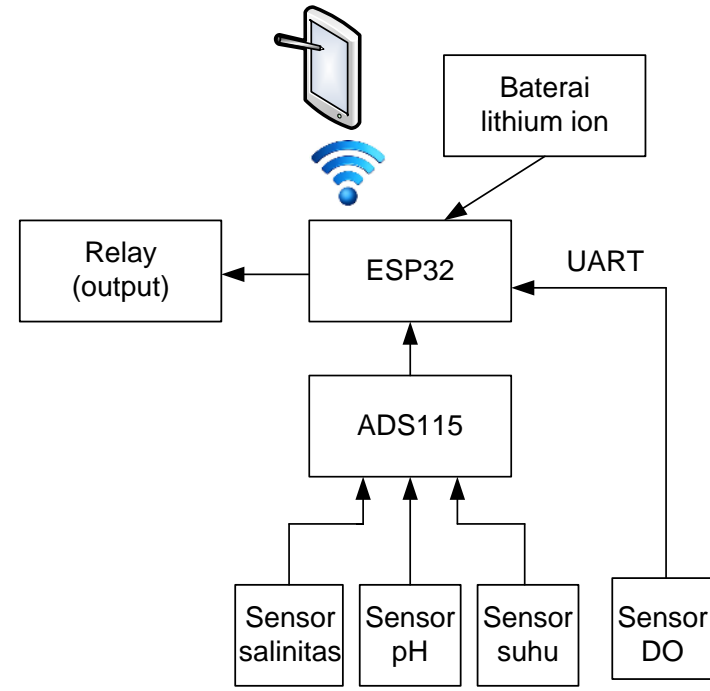

Gambar 3 Diagram Perangkat Keras pada Koper

\section{Perangkat Lunak}

Sistem ini menggunakan bahasa pemrograman Arduino. Pemrograman yang dibuat adalah pembacaan data sensor serial, data sensor analog, konversi data analog ke digital, koneksi ke Blynk, pengiriman data ke Blynk, seperti terlihat pada diagram alir Gambar 4.

Diagram alir pada perangkat lunak dimulai dari deteksi koneksi internet yang terhubung dengan server Blynk. Jika ada koneksi internet, sensor mulai mengirimkan data dan ESP32 menerima data tersebut untuk diteruskan ke server Blynk. Setelah server pada Blynk terupdate data akan ditampilkan pada aplikasi Blynk di smartphone.

\section{HASIL DAN PEMBAHASAN}

Sistem pemonitor kualitas air telah dibuat dan berhasil dikembangkan menggunakan perangkat keras, perangkat lunak, dan arsitektur yang telah dirancang. Untuk menguji performansi sistem monitoring kualitas air, percobaan dibawa ke kolam ikan. Parameter kualitas air di set seperti pada Tabel 1.

TABEL I. STANDAR PARAMETER AIR

\begin{tabular}{|l|c|c|}
\hline \multicolumn{1}{|c|}{ Parameter } & Min & Max \\
\hline Suhu & $27^{0} \mathrm{C}$ & $33^{0} \mathrm{C}$ \\
\hline $\mathrm{Ph}$ & 6,8 & 8,0 \\
\hline DO & $4 \mathrm{mg} / \mathrm{l}$ & $10 \mathrm{mg} / \mathrm{l}$ \\
\hline Salinitas & $0 \mathrm{mg} / \mathrm{l}$ & $1 \mathrm{mg} / \mathrm{l}$ \\
\hline
\end{tabular}

Gambar 5 menunjukkan implementasi sistem. Koper alumunium dengan empat sensornya dan perangkat elektronik ditempatkan di dekat kolam yang akan diukur kualitas airnya dan empat sensor direndam di kolam. 


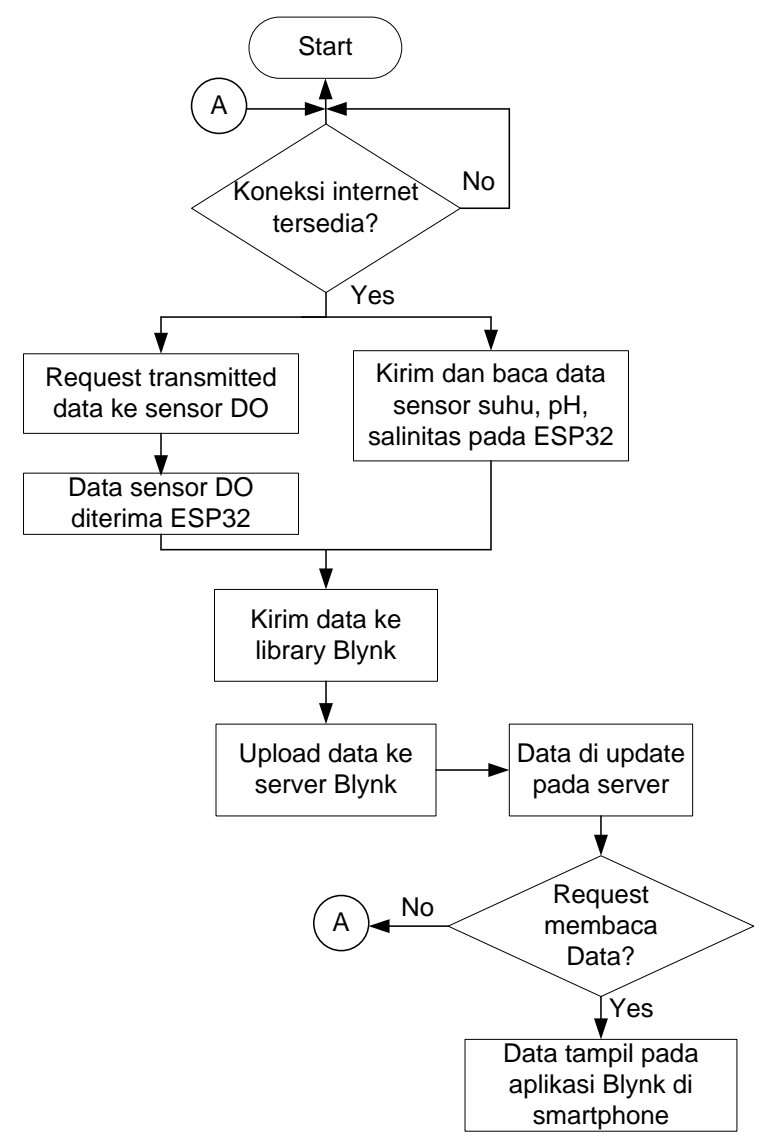

Gambar 4 Diagram Alir Perangkat Lunak

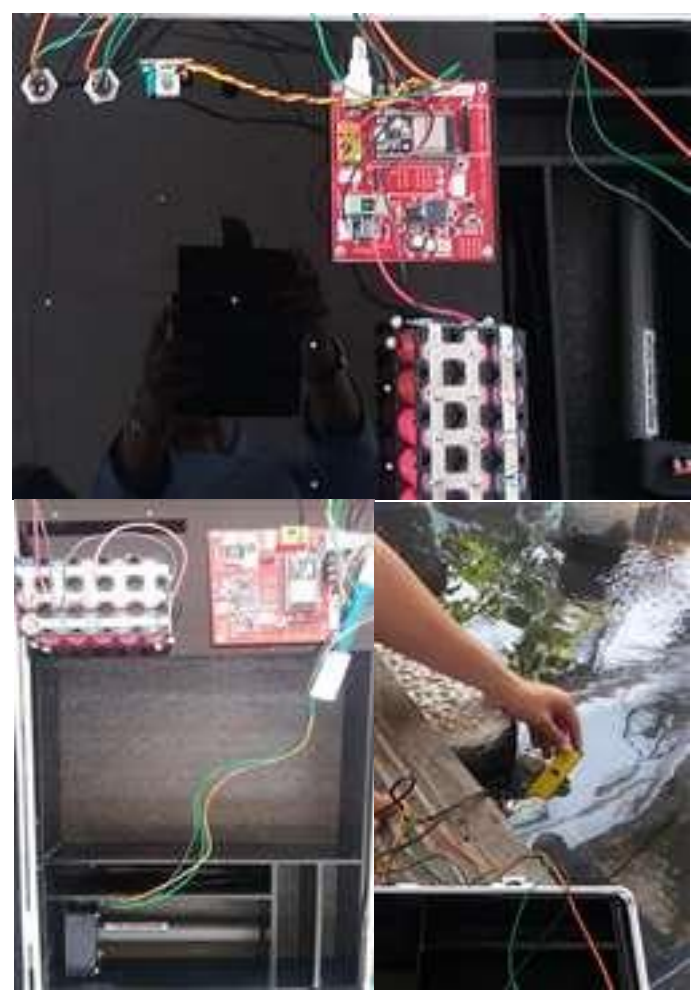

Gambar 5 Implementasi Sistem
Sistem ini mempunyai arus 0,85 A, dengan menggunakan baterai lithium ion sebesar 13,500 $\mathrm{mA} / \mathrm{jam}$, maka sistem mampu bekerja sekitar 114,75 jam. Ini lebih dari cukup untuk bukti konsep prototipe ini. Hasil pengukuran dapat dilihat pada Gambar 6.

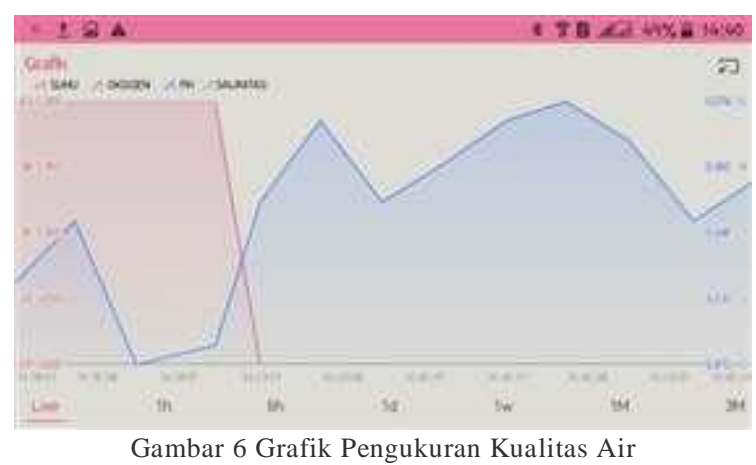

Data sensor dikirim ke Blynk per detik. Dari Gambar 6 terlihat bahwa pada jam 14:40:01 WIB tampil data: Suhu $31{ }^{\circ} \mathrm{C}$, DO 5 ppm, pH 6,940, dan salinitas $0 \mathrm{~g} / \mathrm{l}$. Untuk nilai parameter DO dan salinitas selalu stabil di $5 \mathrm{ppm}$ dan $0 \mathrm{~g} / \mathrm{l}$. sedangkan nilai suhu dapat naik ataupun turun sesuai dengan kondisi cuaca. Contohnya, pada jam 14:39:55 WIB suhu mencapai $41^{\circ} \mathrm{C}$, namun pada jam 14:40:01 suhu turun menjadi $31^{\circ} \mathrm{C}$ dan stabil terus pada suhu tersebut hingga sore hari. Nilai $\mathrm{pH}$ juga cenderung stabil di rentang nilai $6,919-7$.

Untuk melihat data pengukuran kualitas air dapat menggunakan smartphoneltablet dalam aplikasi Blynk seperti terlihat pada Gambar 7. Dari Gambar 7 terlihat bahwa data masing-masing sensor muncul pada display smartphone. Selain itu, history data juga muncul dalam bentuk grafik. Histori data ini dapat dikirim ke owner jika diperlukan melalui email dalam bentuk data.csv.

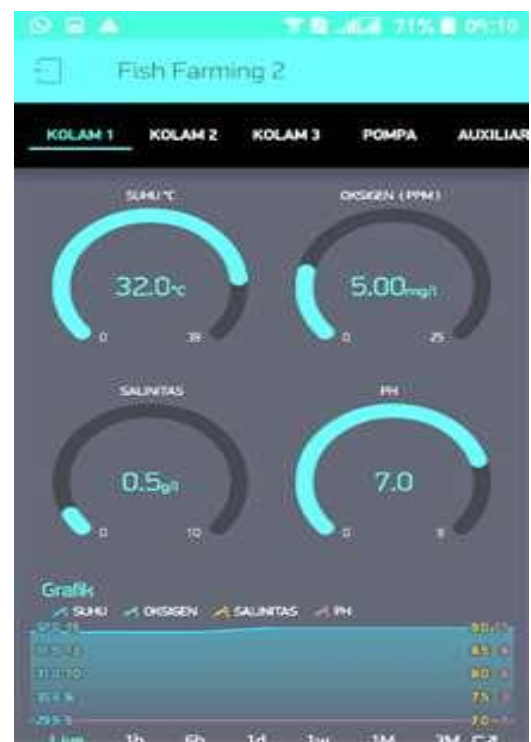

Gambar 7 Tampilan Data pada Tablet dalam Aplikasi Blynk 
Apabila terjadi kondisi pembacaan sensor diluar rentang nilai yang diizinkan maka akan muncul notifkasi di smartphone seperti terlihat pada Gambar 8.

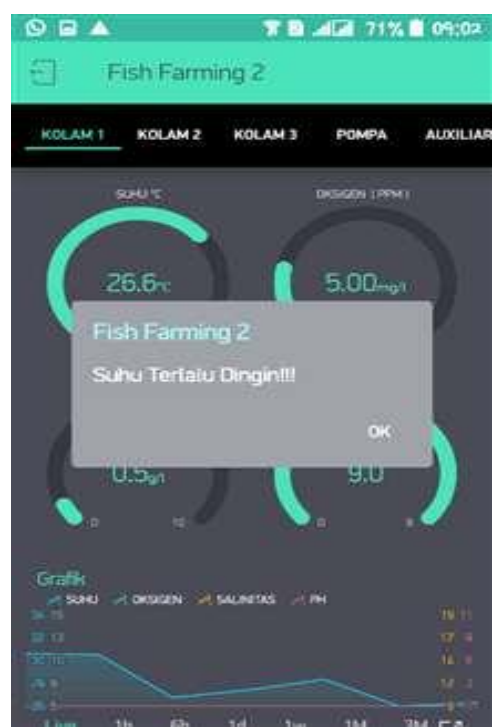

Gambar 8 Tampilan Notifikasi pada Tablet dalam Aplikasi Blynk

Pada Gambar 8 terlihat bahwa suhu yang terjadi adalah $26,6^{\circ} \mathrm{C}$. Karena suhu ini berada di luar rentang nilai yang diizinkan maka muncul notifikasi "Suhu Terlalu Dingin". Begitu pula dengan parameter yang lain jika terjadi pembacaan diluar rentang nilai akan muncul notifikasi ini.

\section{KESIMPULAN}

Penelitian ini menyajikan implementasi prototipe tentang konsep sistem pemantauan jarak jauh dengan teknologi iot yang ditujukan untuk memonitor kualitas air pada perikanan budidaya. hasil pengujian membuktikan bahwa sistem telah bekerja dengan baik dan mampu mengukur nilai parameter air berupa $\mathrm{pH}$, suhu, salinitas, dan DO.

\section{REFERENSI}

[1] M. Phillips et al., "Menjelajahi masa depan perikanan budidaya Indonesia (Exploring Indonesian aquaculture futures)," 2016.

[2] G. Wiranto and I. D. P. Hermida, "Pembuatan Sistem Monitoring Kualitas Air Secara Real-Time dan Aplikasinya Dalam Pengelolahan Tambak Udang," Jurnal Teknologi Indonesia, vol. 33, no. 2, pp. 107-113, 2010.

[3] M. F. Fuady and M. Nitisupardjo, "Pengaruh Pengelolaan Kualitas Air Terhadap Tingkat Kelulushidupan Dan Laju Pertumbuhan Udang Vaname (Litopenaeus Vannamei) Di Pt. Indokor Bangun Desa, Yogyakarta," Management of Aquatic Resources Journal, vol. 2, no. 4, pp. 155-162, 2013.

[4] A. E. Multazam and Z. B. Hasanuddin, "Sistem monitoring kualitas air tambak udang vaname," JURNAL IT: Media Infromasi STMIK Handayani Makassar, vol. 8, no. 2, pp. 118-125, 2017.

[5] I. Espinosa-Curiel, H. Pérez-Espinosa, J. GonzálezGonzález, and J. Rodríguez-Jacobo, "A mobile platform for remote monitoring of water quality on live fish transport containers: Lessons learned," in 2016 International Conference on Electronics, Communications and Computers (CONIELECOMP), 2016, pp. 40-47: IEEE.

[6] X. Zhu, D. Li, D. He, J. Wang, D. Ma, and F. Li, "A remote wireless system for water quality online monitoring in intensive fish culture," Computers and Electronics in Agriculture, vol. 71, pp. S3-S9, 2010

[7] C. Encinas, E. Ruiz, J. Cortez, and A. Espinoza, "Design and implementation of a distributed IoT system for the monitoring of water quality in aquaculture," in 2017 Wireless Telecommunications Symposium (WTS), 2017, pp. 1-7: IEEE.

[8] L. Hongpin, L. Guanglin, P. Weifeng, S. Jie, and B. Qiuwei, "Real-time remote monitoring system for aquaculture water quality," International Journal of Agricultural and Biological Engineering, vol. 8, no. 6, pp. 136-143, 2015.

[9] S. Ferdoush and X. Li, "Wireless sensor network system design using Raspberry Pi and Arduino for environmental monitoring applications," Procedia Computer Science, vol. 34, pp. 103-110, 2014.

[10] D. Nguyen Tang Kha, T. Nguyen Dinh, S. Tra Hoang, and K. Luong Hong Duy, "Automated monitoring and control system for shrimp farms based on embedded system and wireless sensor network," in 2015 IEEE International Conference on Electrical, Computer and Communication Technologies (ICECCT), 2015, pp. 1-5.

[11] E. Systems, "ESP32Technical Reference Manual," E. Inc, Ed., 4.1 ed, 2019

[12] B. Earl, "Overview ADS1115," Available: https://learn.adafruit.com/adafruit-4-channel-adcbreakouts/overview

[13] T. Instruments, "LM35," ed, 2017.

[14] DFRobot, ed.

[15] A. S. LLC, "Dissolved Oxygen Probe," ed, 2019. 